\title{
Short-term maraviroc exposure, a clinical approach to decide on maraviroc prescription in HIV-I-infected treatment-naïve patients
}

This article was published in the following Dove Press journal:

Drug Design, Development and Therapy

18 January 2016

Number of times this article has been viewed

\author{
Alejandro Gonzalez-Serna' \\ Miguel Genebat ${ }^{2}$ \\ Ezequiel Ruiz-Mateos ${ }^{2}$ \\ Manuel Leal ${ }^{2}$ \\ 'Laboratory of Molecular \\ Immunobiology, Hospital General \\ Universitario Gregorio Maranon, \\ Madrid, ${ }^{2}$ Laboratory of Immunovirology, \\ Institute of Biomedicine of Seville, \\ Seville, Spain
}

\section{Dear editor}

Woollard and Kanmogne ${ }^{1}$ have generated an exhaustive review on maraviroc and its use in human immunodeficiency virus (HIV) infection. Within their interesting dissertation, they discuss about the maraviroc clinical test (MCT), a clinical approach developed in our group in order to decide candidate patients to receive maraviroc as part of a further combined antiretroviral therapy, as an alternative to genotypic and phenotypic tropism assays. ${ }^{2}$ Based on our results, they state that MCT could help to determine/confirm the genotypic/phenotypic HIV-1 tropism, particularly in patients with nonreportable results by Trofile ${ }^{\circledR}$. Subsequently, they note that "no concordance" between standard V3-based genotypic tropism assays and virological response to maraviroc monotherapy was found, according to previous results generated by our group. ${ }^{3}$ Finally, based on the results of Hernández-Novoa et al, ${ }^{4}$ they conclude that short-term maraviroc exposure cannot predict viral tropism in treatment-naïve patients.

In our opinion, MCT is an alternative tool to be used in clinical practice to decide CCR5-antagonist prescription in HIV-infected subjects, both in treatment-experienced and -naïve patients. Discordances between phenotypic and genotypic methods have been found. ${ }^{5}$ Moreover, our group developed MCT, a drug sensitivity test but not a tropism assay, and again discordances between MCT and different tropism methods including deep-sequencing were found. ${ }^{5,6}$ Hence, it has not been established as a "gold standard" to be used in clinical practice before prescribing maraviroc. We consider that the virological response to the drug should be the most important criteria in order to decide maraviroc prescription, and not a categorical tropism result. Therefore, we use MCT not just to confirm a genotypic/phenotypic tropism result and not particularly in patients with a nonreportable result by Trofile ${ }^{\circledR}$ but in all patients.

Regarding the naïve scenario, our group has explored this issue in a recently published work, ${ }^{7}$ confirming that MCT is a reliable tool to decide maraviroc prescription in naïve HIV-infected subjects. In this work, most patients showed a significant viral load reduction during MCT and an excellent immunovirological evolution was shown once the subsequent cART was started after MCT; again, discordance rates were found between MCT and different tropism methods, similar to those found in treatmentexperienced patients. ${ }^{2,5,6}$ Unfortunately, the review by Woollard and Kanmogne ${ }^{1}$ was accepted for publication just before the publication of this work, so they probably did not have time to include our data in their study. 
Additionally, Woollard and Kanmogne consider that MCT cannot be used in naïve HIV-infected subjects based on data from Hernández-Novoa et $\mathrm{al},{ }^{4}$ because these authors concluded that this clinical test cannot be used as a surrogate marker of viral tropism in naïve patients. We agree with the conclusion of Hernández-Novoa et al, since MCT is not a surrogate marker of viral tropism but a clinical test based on the virological response to a short-term exposure to the drug, and provides discordant results with different tropism assays as previously reported. ${ }^{2,5,6}$ Hernández-Novoa et al show that patients with R5 or dual/mixed viral tropism according to Trofile ${ }^{\circledR}$ have similar virological responses to maraviroc monotherapy, reflecting the previously described discordance between the clinical approach and the phenotypic tropism method, as expected. Analyzing their data, we can see that $32 / 37$ (85\%) of their patients had virological response according to MCT (viral load reduction $>1$ log RNA copies/ $\mathrm{mL}$ ) while 5/37 (15\%) did not, exactly the R5 and non-R5 expected percentages in HIV-1 treatment-naïve patients. ${ }^{8}$ In addition, given the MCT criteria, $9 / 37$ (24\%) of the patients had discordant results with Trofile ${ }^{\circledR}$ in their study, similar to previous studies. ${ }^{2,5-7}$ Besides, unlike Hernández-Novoa et al, in these mentioned studies we performed a follow-up of the patients proving the safety of the test according to the excellent immunovirological evolution after long-term cART started after MCT. Therefore, we consider that a misclassification by Trofile ${ }^{\circledR}$ and genotypic methods would be the more plausible explanation for the discordances observed with the virological response during maraviroc monotherapy exposure, probably due to the presence of low-level X4 variants with no clinical relevance.

Taken altogether, we think that MCT remains a very promising strategy to decide maraviroc prescription in HIVinfected patients, both treatment-experienced and -naïve subjects, independent of the viral tropism result once the presence of low-level X4 variants seem to be clinically irrelevant.

\section{Acknowledgments}

We would like to acknowledge the patients who participated in this study. This work was supported by Redes Tematicas de Investigacion en SIDA (ISCIII RETIC RD12/0017/0029) and Fondo de Investigación Sanitaria (PI12/02283).

\section{Disclosure}

A Gonzalez-Serna and M Genebat contributed equally as first authors. E Ruiz-Mateos and M Leal contributed equally as last authors. E Ruiz-Mateos has a grant from Fondo de Investigaciones Sanitarias (CP08/00172 and CPII014/00025). M Leal and E Ruiz-Mateos have grants from Pfizer/ViiV Healthcare. The authors report no other conflicts of interest in this communication.

\section{References}

1. Woollard SM, Kanmogne GD. Maraviroc: a review of its use in HIV infection and beyond. Drug Des Devel Ther. 2015;9:5447-5468.

2. Genebat M, Ruiz-Mateos E, Leon JA, et al. Correlation between the Trofile test and virological response to a short-term maraviroc exposure in HIV-infected patients. J Antimicrob Chemother. 2009;64:845-849.

3. Gonzalez-Serna A, McGovern RA, Harrigan PR, et al. Correlation of the virological response to short-term maraviroc monotherapy with standard and deep-sequencing-based genotypic tropism prediction methods. Antimicrob Agents Chemother. 2012;56:1202-1207.

4. Hernández-Novoa B, Madrid-Elena N, Dronda F, et al. Virological response to short-course maraviroc monotherapy does not predict viral tropism in HIV-1-infected treatment-naive patients. J Antimicrob Chemother. 2014;69:1916-1919.

5. Gonzalez-Serna A, Leal M, Genebat M, et al. TROCAI (tropism coreceptor assay information): a new phenotypic tropism test and its correlation with Trofile enhanced sensitivity and genotypic approaches. J Clin Microbiol. 2010;48:4453-4458.

6. Genebat M, Ruiz-Mateos E, González-Serna A, et al. Discordance rates between Trofile test and short-term virological response to maraviroc. Antiviral Res. 2011;89:182-185.

7. Genebat M, de Pablo-Bernal RS, Pulido I, et al. Maraviroc Clinical Test (MCT) as an alternative tool to decide CCR5-antagonists prescription in naïve HIV-infected patients. Antiviral Res. 2015;121:94-96.

8. Moyle GJ, Wildfire A, Mandalia S, et al. Epidemiology and predictive factors for chemokine receptor use in HIV-1 infection. J Infect Dis. 2005; 191:866-872. 


\section{Author's reply \\ Shawna M Woollard \\ Georgette D Kanmogne}

Department of Pharmacology and Experimental Neuroscience, University of Nebraska Medical Center, Omaha, NE, USA

Correspondence: Georgette D Kanmogne

Department of Pharmacology and Experimental Neuroscience,

University of Nebraska Medical Center, 985800 Nebraska Medical

Center, Omaha, NE, USA

$\mathrm{Tel}+$ I 4025594084

Fax +l 4025597495

Email gkanmogne@unmc.edu

\section{Dear editor}

We appreciate the insightful comments of Gonzalez-Serna et al, and their clarifications on the topic of maraviroc clinical test (MCT). In our manuscript, ${ }^{1}$ we reviewed and discussed MCT use as a surrogate marker for viral tropism. We concluded that MCT could not be used as an alternative approach to test for viral tropism based on a study by Hernández-Novoa et al, ${ }^{2}$ showing that treatment-naïve patients with dual $/$ mixed tropic human immunodeficiency virus (HIV) strains showed a positive MCT response. However, we did not address the possibility of the MCT as a clinical alternative to genotypic and phenotypic tropism assays.

We agree that the clinical utility of the MCT should not be overlooked, especially in patients with nonreportable Trofile $^{\circledR}$ results or when there are discordant results between genotypic and phenotypic tropism assays. However, we remain concerned about the possibility of the outgrowth of X4-tropic viruses. We believe that when $\mathrm{X} 4$ variants are present in subjects with dual/mixed tropic HIV strains, the fact that the levels of those initial X4 variants are low, and that subjects initially respond to MVC therapy, do not make the X4 variants clinically irrelevant. There are several studies showing that after initial success following antiretroviral therapy targeting non-X4 variants, even with significant virological and immunological responses, initial low-level X4 variants can outgrow ${ }^{3,4}$ and this often leads to resistance and treatment failure..$^{3-6}$

Thus, these initial low levels of X4 variants can have major clinical implications and relevance.

The MCT may be more appropriate for infected treatment-naïve subjects, compared to infected treatmentexperienced patients, as X4 variants in the viral reservoirs are more likely to have emerged in most patients in the latter group compared to treatment-naïve patients. ${ }^{78}$ This is corroborated by studies showing reduced viral loads in treatment-naïve patients with dual/mixed tropic HIV strains during the MCT,, 9 whereas another study performed in treatment-experienced patients with dual/mixed HIV strains showed no decrease in viral load during the MCT in the majority of patients. ${ }^{10}$ Maraviroc therapy, even in patients with low levels of $\mathrm{X} 4$ variants, may lead to the emergence of X4 variants from the viral reservoir, ${ }^{3,11}$ possibly due to increased fitness of the X4-tropic virus over R5-tropic virus. ${ }^{12}$ The long-term effects of the emergence of $\mathrm{X} 4$ variants during treatment with maraviroc remain unknown, but such a development could be clinically significant and relevant, and could be a major concern in patients with multiclass drug resistance.

The major limitations of the MCT studies thus far have been the low number of patients/sample size in each study, and the lack of data showing the efficacy of maraviroccontaining regimens in patients with a positive $\mathrm{MCT}$ at time points past 144 weeks. . $, 9,10,13-17$ We look forward to future results with the MCT involving larger cohorts and longer follow-up time points.

\section{Disclosure}

The authors report no conflicts of interest in this communication.

\section{References}

1. Woollard SM, Kanmogne GD. Maraviroc: a review of its use in HIV infection and beyond. Drug Des Devel Ther. 2015;9:5447-5468.

2. Hernández-Novoa B, Madrid-Elena N, Dronda F, et al. Virological response to short-course maraviroc monotherapy does not predict viral tropism in HIV-1-infected treatment-naive patients. J Antimicrob Chemother. 2014;69(7):1916-1919.

3. Westby M, Lewis M, Whitcomb J, et al. Emergence of CXCR4-using human immunodeficiency virus type 1 (HIV-1) variants in a minority of HIV-1-infected patients following treatment with the CCR5 antagonist maraviroc is from a pretreatment CXCR4-using virus reservoir. $J$ Virol. 2006;80(10):4909-4920.

4. Baatz F, Struck D, Lemaire M, et al. Rescue of HIV-1 long-time archived X4 strains to escape maraviroc. Antiviral Res. 2011;92(3):488-492.

5. Recordon-Pinson P, Raymond S, Bellecave $P$, et al. HIV-1 dynamics and coreceptor usage in Maraviroc-treated patients with ongoing replication. Antimicrob Agents Chemother. 2013;57(2):930-935.

6. Swenson LC, Chui CK, Brumme CJ, et al. Genotypic analysis of the V3 region of HIV from virologic nonresponders to maraviroc-containing regimens reveals distinct patterns of failure. Antimicrob Agents Chemother. 2013;57(12):6122-6130.

7. Delobel P, Sandres-Saune K, Cazabat M, et al. R5 to X4 switch of the predominant HIV-1 population in cellular reservoirs during effective highly active antiretroviral therapy. J Acquir Immune Defic Syndr. 2005; 38(4):382-392.

8. Moore JP, Kitchen SG, Pugach P, Zack JA. The CCR5 and CXCR4 coreceptors - central to understanding the transmission and pathogenesis of human immunodeficiency virus type 1 infection. AIDS Res Hum Retroviruses. 2004;20(1):111-126.

9. Genebat M, de Pablo-Bernal RS, Pulido I, et al. Maraviroc clinical test (MCT) as an alternative tool to decide CCR5-antagonists prescription in naive HIV-infected patients. Antiviral Res. 2015;121:94-96.

10. Genebat M, Ruiz-Mateos E, Leon JA, et al. Correlation between the Trofile test and virological response to a short-term maraviroc exposure in HIV-infected patients. J Antimicrob Chemother. 2009;64(4):845-849. 
11. Archer J, Braverman MS, Taillon BE, et al. Detection of low-frequency pretherapy chemokine (CXC motif) receptor 4 (CXCR4)-using HIV-1 with ultra-deep pyrosequencing. AIDS. 2009;23(10):1209-1218.

12. Nankya IL, Tebit DM, Abraha A, et al. Defining the fitness of HIV-1 isolates with dual/mixed co-receptor usage. AIDS Res Ther. 2015;12:34.

13. Genebat M, Ruiz-Mateos E, Pulido I, et al. Long-term immunovirogical effect and tolerability of a maraviroc-containing regimen in routine clinical practice. Curr HIV Res. 2010;8(6):482-486.

14. Genebat M, Ruiz-Mateos E, Gonzalez-Serna A, et al. Discordance rates between Trofile test and short-term virological response to maraviroc. Antiviral Res. 2011;89(2):182-185.
15. Genebat M, Pulido I, Romero-Sanchez MC, et al. Patients on a combined antiretroviral therapy after maraviroc clinical test show no immunovirological impairment. Antiviral Res. 2012;95(3):207-211.

16. Gonzalez-Serna A, McGovern RA, Harrigan PR, et al. Correlation of the virological response to short-term maraviroc monotherapy with standard and deep-sequencing-based genotypic tropism prediction methods. Antimicrob Agents Chemother. 2012;56(3):1202-1207.

17. Gonzalez-Serna A, Romero-Sanchez MC, Ferrando-Martinez S, et al. HIV-1 tropism evolution after short-term maraviroc monotherapy in HIV-1-infected patients. Antimicrob Agents Chemother. 2012;56(7): $3981-3983$.

Dove Medical Press encourages responsible, free and frank academic debate. The content of the Drug Design, Development and Therapy 'letters to the editor' section does not necessarily represent the views of Dove Medical Press, its officers, agents, employees, related entities or the Drug Design, Development and Therapy editors. While all reasonable steps have been taken to confirm the content of each letter, Dove Medical Press accepts no liability in respect of the content of any letter, nor is it responsible for the content and accuracy of any letter to the editor.

\section{Dovepress}

\section{Publish your work in this journal}

Drug Design, Development and Therapy is an international, peerreviewed open-access journal that spans the spectrum of drug design and development through to clinical applications. Clinical outcomes, patient safety, and programs for the development and effective, safe, and sustained use of medicines are a feature of the journal, which has also been accepted for indexing on PubMed Central. The manuscript management system is completely online and includes a very quick and fair peer-review system, which is all easy to use. Visit http://www.dovepress.com/testimonials.php to read real quotes from published authors.

Submit your manuscript here: http://www.dovepress.com/drug-design-development-and-therapy-journal 